العدد الحادي والأربعون

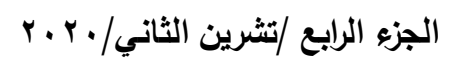

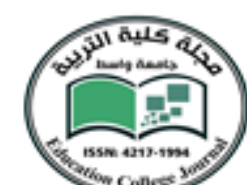

\title{
مجالات تصحيح الحديث الضعيف
}

م.د. عبد الوهاب ققوري العبيدي

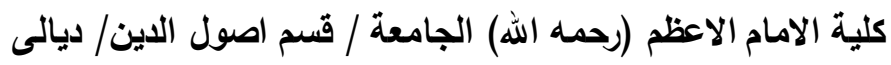

abdalwahaab2020@gmail.com

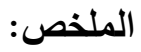

ان دراسة السنة النبوية من الأمور التي تزيد المسلم قربا من الله تعالى الانها تعمل على الهى

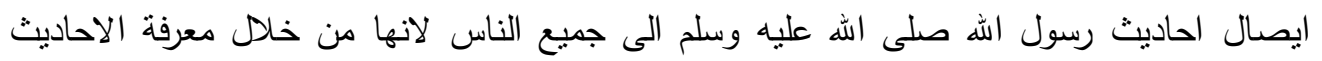

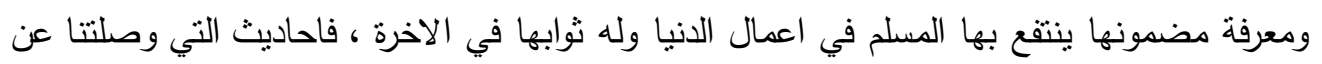
ضوع مختلق كذبا وزور عن رسول اله صلى الله عليه وسلم ، هنا ننوقف مع مجالات تصحيح

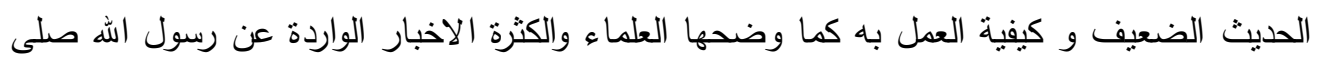

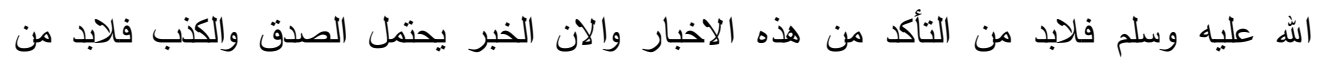

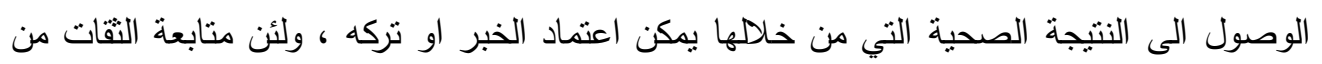

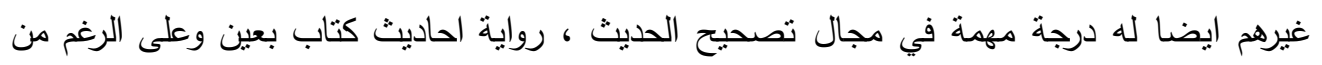

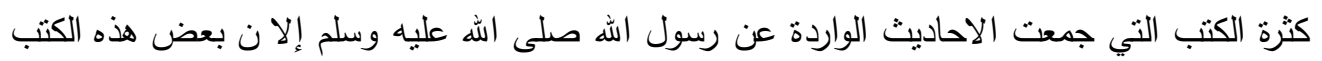

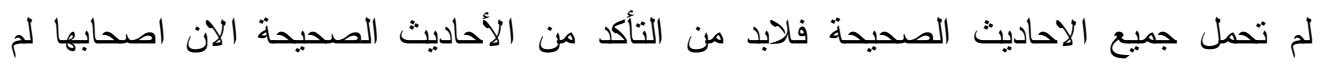

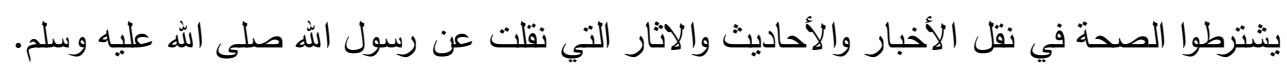

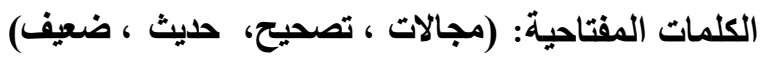




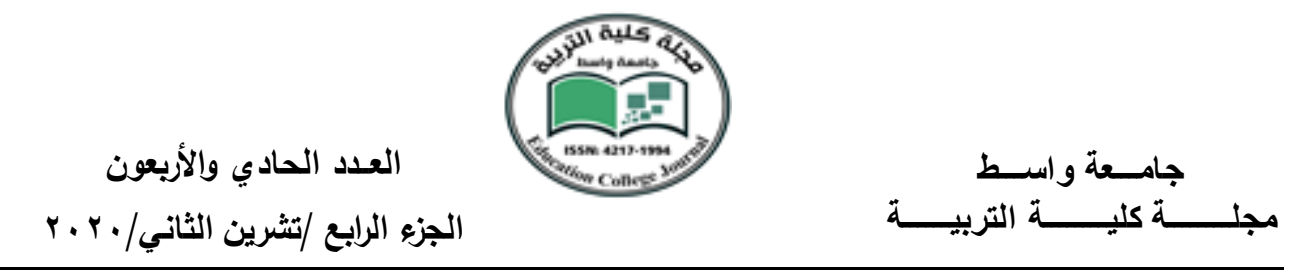

Areas of poor speech correction

Dr.

Abdul wahab kadoorey Ahmed Rahim Al obadi

Imam Al-Azam College

Department of Religion Assets/Diyala

\begin{abstract}
:
The study of the Prophet's Sunnah is one of the things that make the Muslim closer to Allaah because it works to communicate the hadiths of the Prophet(pbuh) to all people, because through knowing the hadiths and knowing their content, the Muslim will benefit from the actions of the world and he has the rewards in the afterlife. Here we stop with the areas of correction of weak talk and how to work with it as explained by the scholars and the many news received about the Messenger of Allah, peace be upon him, it is necessary to confirm this news and now the news is possible truth and lies, it is necessary to reach the health result through which the news can be adopted or left behind ,Despite the many books that have collected the hadiths received about the Prophet, but some of these books did not carry all the correct hadiths, it is necessary to make sure that the correct hadiths are now not required to transmit the news, hadiths and relics that were quoted from the Messenger of God, peace be upon him, the way of the modern storytellers and men of the right support, some of which are good, including the weak ones. About the seizure of a particular news, and the second topic: a novel of the hadiths of a particular book. The most important results The Prophet's Sunnah and the hadiths of The Prophet(PBUH) have been divided by scholars into four main sections, which are correct, good, weak and subject Scientists have set conditions for working with weak talk. The words of the scholars in the ruling of protest ing the weak talk through the conditions set for him. The weakness of the novel is the result of many mistakes and illusions of the narrator. Rawi's novel rejects his account through the sayings of the wounded and the modified .The news must be controlled because it has an impact on the narrator in terms of accepting his account from its response To accept the novel
\end{abstract}

Key word: Areas, of poor, speech, correction 
العدد الحادي والأربعون

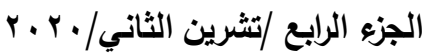

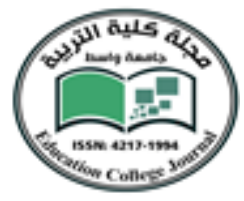

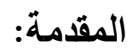

إن الحمد لله، نحمده ونستعينهُ ونستهديه، ونعوذٌ بالله من شرور أنفسنا وسيئات أعمالنا، من يهذه اله فلا مضل له، ومن يضلل فلا هادي له، وأشهد أن لا إله إلا الله، وحده لا شريك له، الواحد

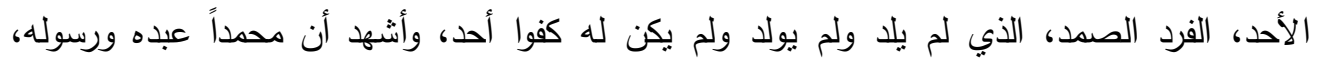

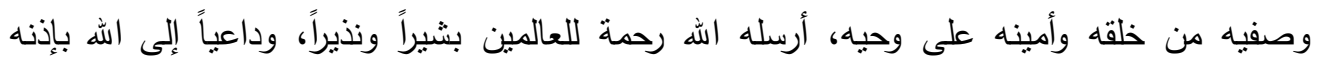

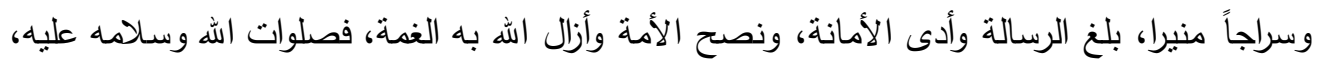

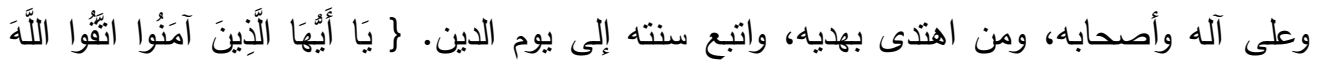

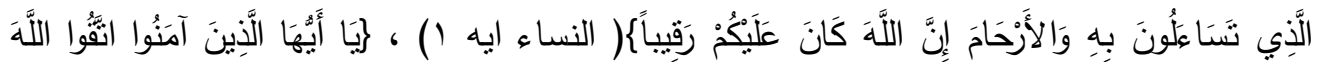

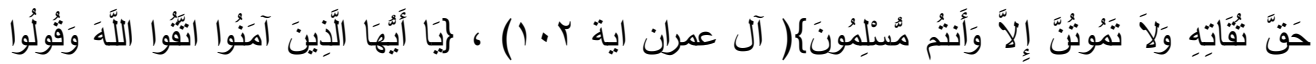

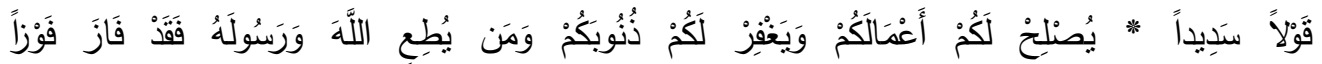

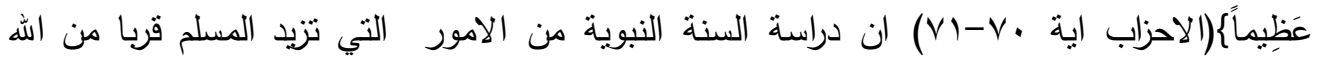
تعالى الانها تعمل على ايصال احاديث رسول اله صلى الله عليه وسلم الى جميع الناس لأنها من خلال معرفة الاحاديث ومعرفة مضمونها ينتقع بها المسلم في اعمال الدنيا وله ثوابها في الآخرة

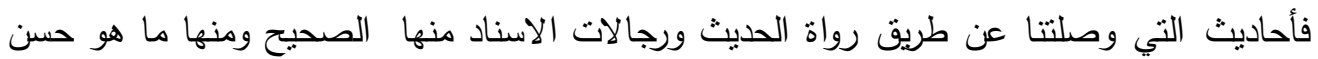

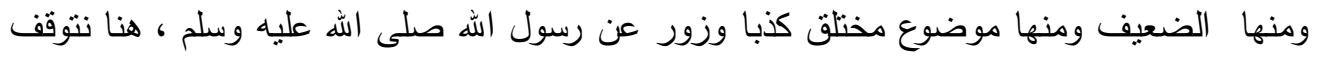
مع مجالات تصحيح الحديث الضعيف و كيفية العمل به كما وضحها العلماء والكثرة الاخبار الواردة عن رسول اله صلى اله عليه وسلم فلابد من التأكد من هذه الاخبار والان الخبر يحتمل الصدق والكنب فلابد من الوصول الى النتيجة الصحية التي من خلالها يمكن اعتماد الخبر او تركه، ولئن

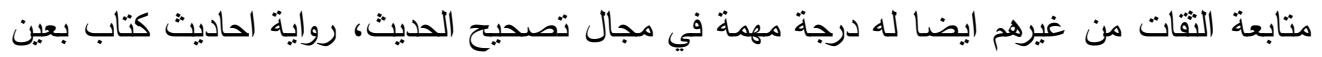
وعلى الرغم من كثرة الكتب التي جمت الاحاديث الواردة عن رسول الله صلى اله عليه وسلم إلان ن بعض هذه الكتب لم تحمل جميع الاحاديث الصحيحة فلابد من التأكد من الاحاديث الصحيحة الان اصحابها لم يشترطوا الصحة في نقل الاخبار والاحاديث والاثار الت نقلت عن رسول الهه صلى الله عليه وسلم فقد نم تقسيم البحث الى تمهيد وثلاثة مباحث الاول يدور حول ضبط خبر بعينه، والمبحث

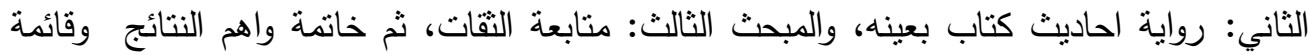
بأهم المصادر فإن وفقت فللك فضل الله وكرمه ومنه وان اخطأت ففللك من نفسي ،واله أسأله التوفيق لما فيه خدمة هذه الدين وخدمة سنة نبيه صلى الله عليه وسلم. الباحث 
العدد الحادي والأربعون

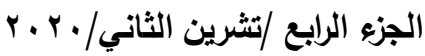

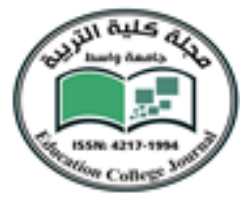

قبل دراسة وبيان مجالات تصحيح الحديث الضعيف لابد من دارسة الحديث الضعيف من ناحية التعريف وحكم العمل به وكذلك اقوال العلماء حول هذا النوع من الاحاديث ولئن السنة النبوية

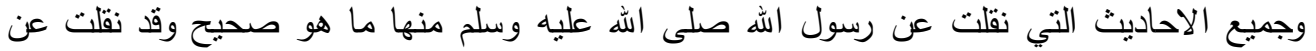
طريق الرواة النقات وقد جمعها الامام البخاري والامام مسلم في صحيحيهما، وكان قبل الاماميين مسلم والبخاري قد الف الامام مالك رحمه الله تعالى كتابه الموطأ ثم الفت كتب السنة الاخرى امثال

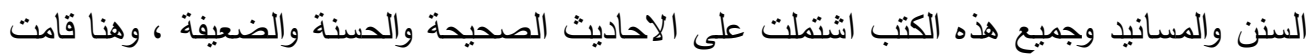
دراستي على بيان مجالات تصحيح الحديث الضعيف ،وقد عرف علماء الحديث :الحديث الضعيف "

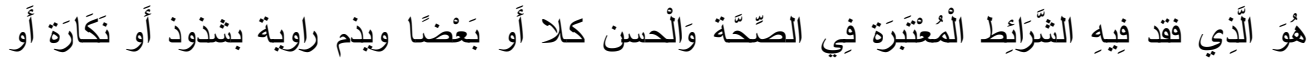

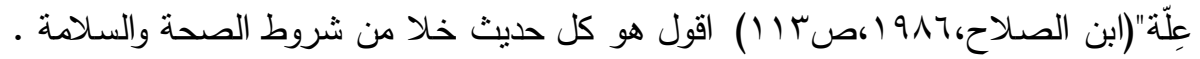
واما من ناحية الاحتجاج بالحديث الضعيف وما اشتهر بين العلماء فقالوا يحتج به ويعمل فِي فَضَّائلِل

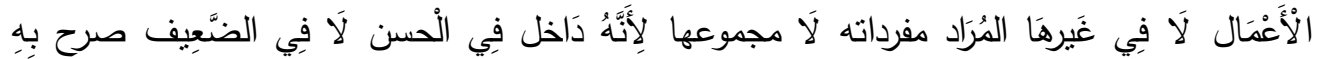

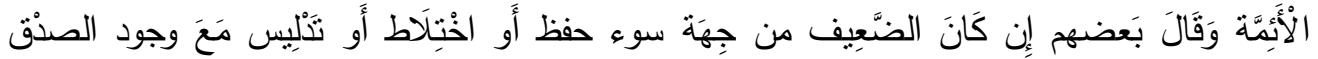

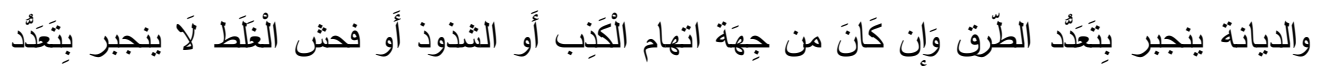

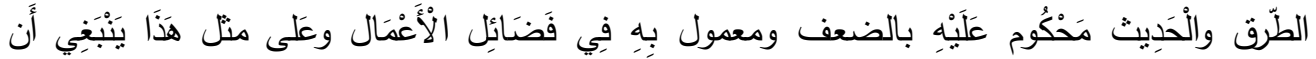

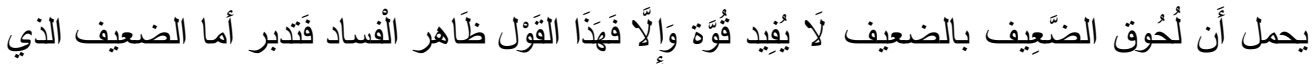
لم يصل إلى حد السقوط والوضع، وهو الضعيف المحتمل فقد اختلفت فيه أنظار العلماء وإليك آراءهم

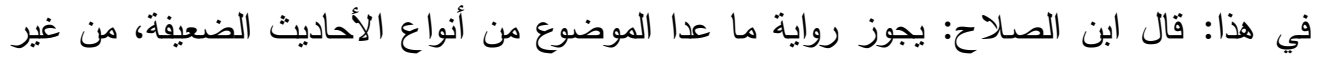

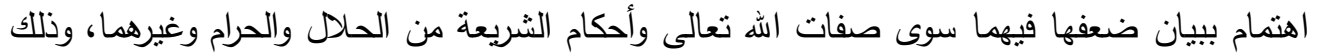
كالمواعظ والقصص، وفضائل الأعمال، وسائر فنون الترغيب والترهيب، وسائر ما لا تعلق له بالأحكام والعقائد، ومقتضى ذلك العمل به فيما ذكر قال: وممن روينا عنه التتصيص على التساهل في نحو ذلك عبد الرحمن بن مهدي، وأحمد بن حنبل رضي اله عنهما. والمراد بفضائل الأعمال:

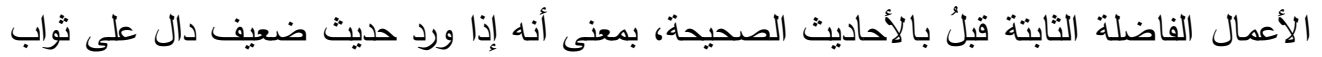

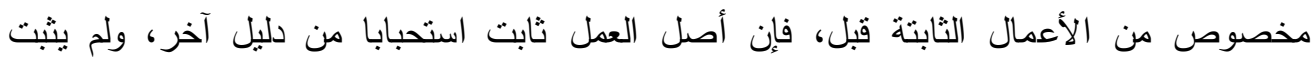

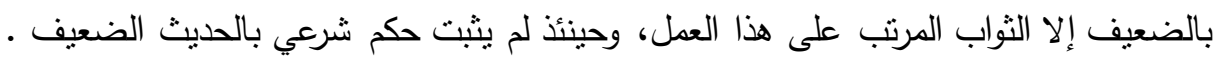

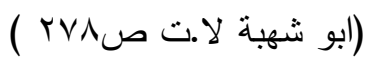


العدد الحادي والأربعون

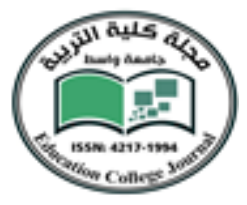

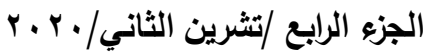

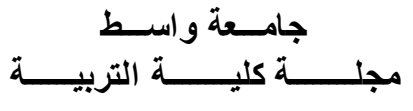

اما اقوال العلماء في حكم العمل بالحديث الضعيف : قال الإمام ابن العربي المالكي لا بعمل به الهابه

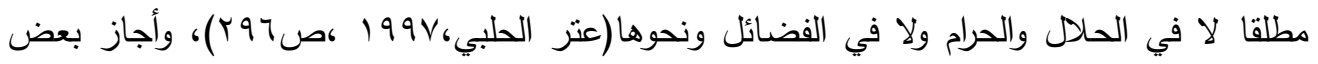
الأئمة رواية الحديث الضعيف بشروط:

1- أن يكون الحديث في القصص، أو المواعظ، أو فضائل الأعمال، أو نحو ذلك مما لا ينعلق بصفات الله، وما يجوز له، وما بستحيل عليه سبحانه، ولا بتفسير القرآن ولا بالأحكام كالحلال

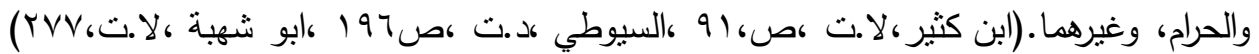
r- أن يكون الضعف فيه غير شديد فيخرج حديث من انفرد من الكذابين والمتهمين بالكنب، والذين فحش غلطهم في الرواية، والحديث الذي كثرت طرقه، ولم تخل طريق منها من شدة الضعف.

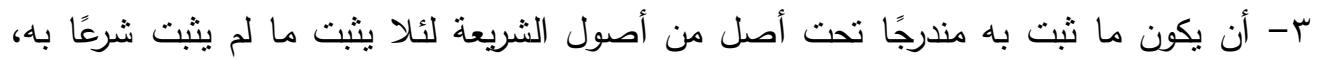

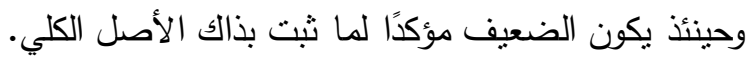
ع - أن لا يعتقد العامل به ثبوته بل يقصد الاحتباط والخروج من العهدة. ه- أن لا بعارضه لليل آخر أقوى منه والحق أنه لا يجوز رواية بلهد الضعيف إلا مقترنًا ببيان ضعفه

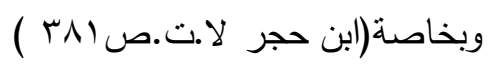

المبحث الاول: ضبط خبر بعينه.

إن الضعف في الرواة جاء من كثرة اخطائهم وذلك لا بعني انه لا يوجد صواب في حديثهم بل

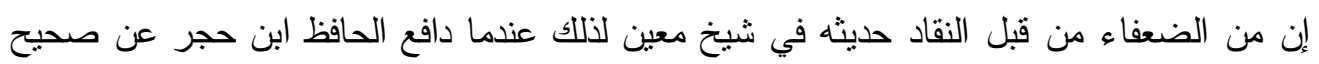

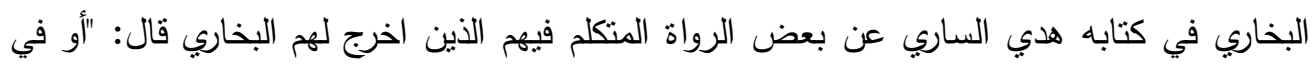

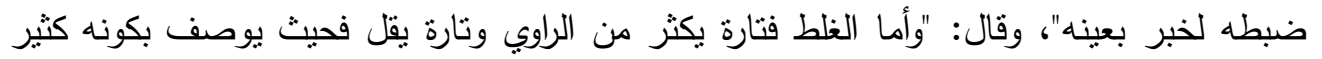

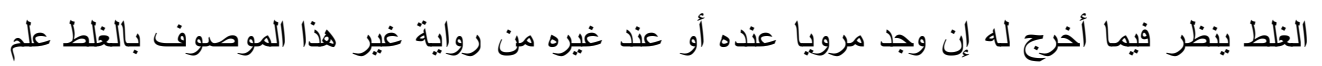

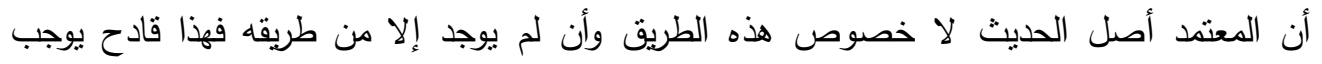
التوقف عن الحكم بصحة ما هذا سبيله وليس في الصحيح بحمد الله من ذلك شئ" (البخاري

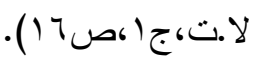

ومن منهج البخاري في صحيحه انه كان براعي ضبط الراوي لخبر بعينه فكان ينتقي من احاديث

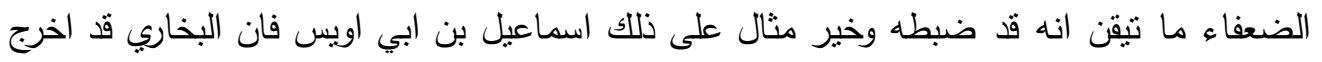

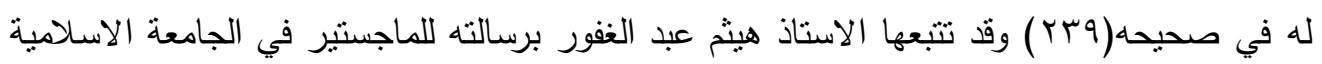

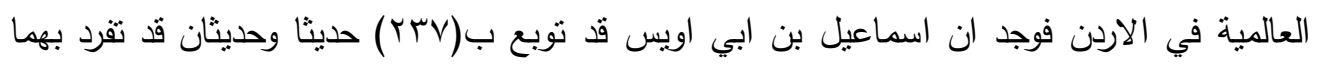


العدد الحادي والأربعون

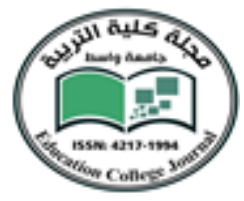

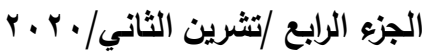

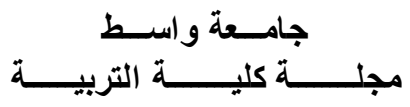

اسماعيل فقط وهي صحيحة بشواهدها، فتبين ان البخاري قد اخرج ما صح من حديثه.ومن احاديثه

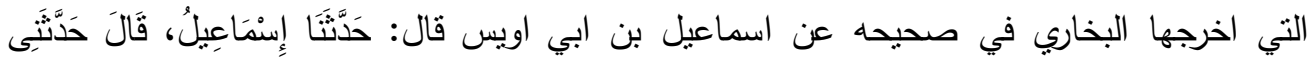

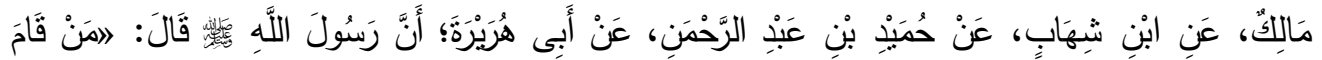

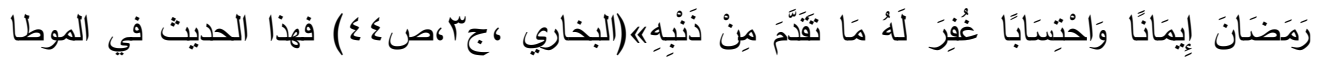

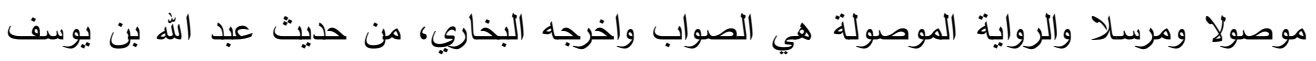

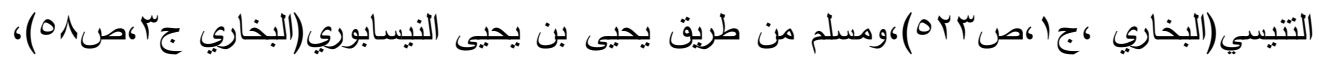
ورواه عبد الرحمن بن مهدي واسحاق بن عيسى البغدادي وقتيبة بن سعيد عن مالك ايضا فضلا عن

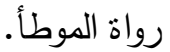

ومثال اخر ممن انتقى لهم البخاري في صحيحه: هشام بن عمار وهو شيخ البخاري ايضا اخرج له

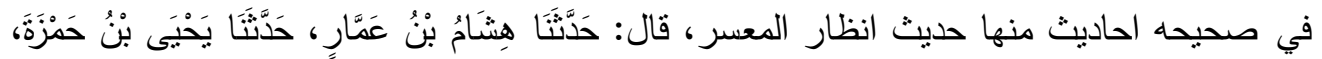

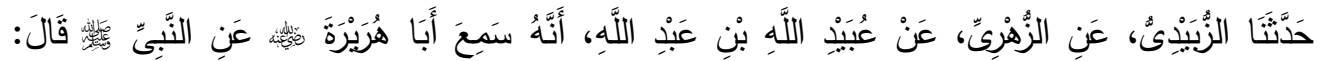

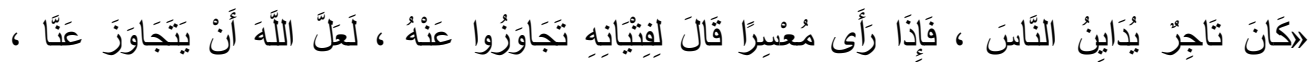

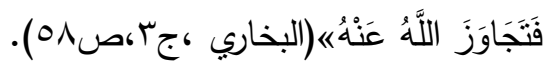
فهذا الحديث قد نوبع هشام بن عمار في شيخ شيخه فقد تابعه عليه((إبراهيم بن سعد، وصالح بن

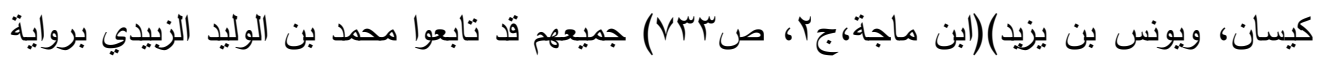
هذا الحديث عن الزهري عن عبيد الله العمري عن ابي هريرة.

\section{المبحث الثاني: رواية احاديث كتاب بعينه..}

هناك من الرواة المتكلم فيهم من يروي كتاب من الكتب المشهورة الرواية فحيئذ تكون روايته كالعدم اذا رويت من قبل تلاميذ اخر غيره وسأمتل على نلك بمثالين:

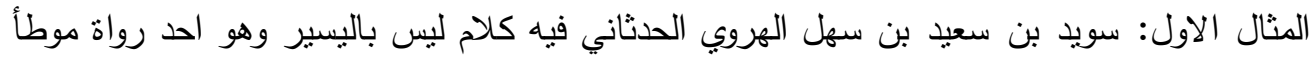

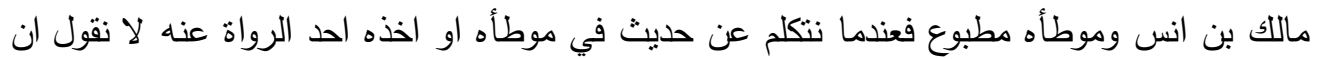
هذا الحديث فيه مقال لان فيه سويد بن سعيد وهو متكلم فيه بل اذا كانت الرواية ثابتة في موطأ الامام ماللك من قبل التلاميذ الثقات الاخر فلا ننظر في سويد بل يكون حكمنا على الحديث من خلال الرواة الذين روى عنهم مالك الحديث. فلو اخذنا مثلا رواية ابن ماجه عنه فقد روى له عن مالك وعن غيره فعندما يكون حديثه عن مالك الك

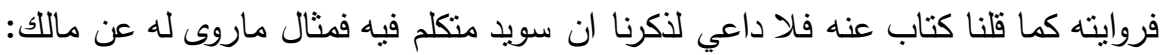


العدد الحادي والأربعون

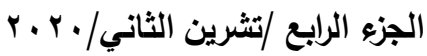

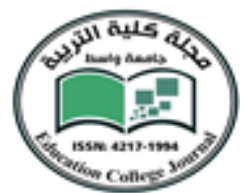

فال ابن ماجه: حدثنا سويد بن سعيد، حدثنا مالك بن أنس، عن نافع، عن ابن عمر؛ أن رسول اله

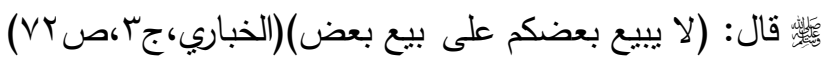
فمن الثقات الذين رووه عن مالك: عبد الرحمن بن مهذي، وحماد بن خالد، كما عند احمد، وعبد الله بن مسلمة القعنبي، وعبد الله بن يوسف التتيسي، وقتيبة بن سعيد، كما عند البخاري، ويحيى بن يحيى

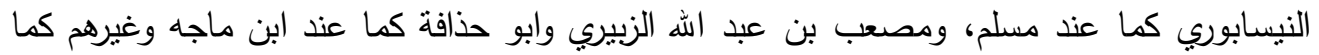

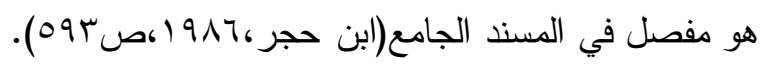
المثال الثاني: يحيى بن عبد الحميد الحماني قال عنه الحافظ ابن حجر في التقريب: حافظ الا انهم

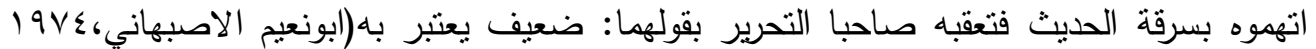

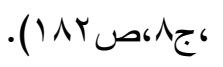

اخرج له ابو نعيم في حلية الاولياء حديثا عن عبد اله بن المبارك فقال: حدثا جعفر بن محمد بن

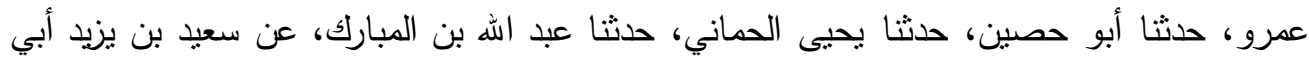

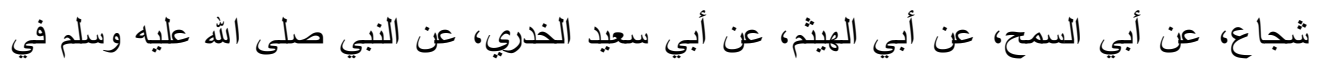
قوله: " تلفح وجوهم النار " ـ قال: " نشويه النار فتقلص شفقتيه العليا حتى تثلغ وسط رأسها، وتسترخي

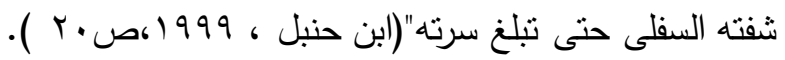
فهذا الحديث قد رواه يحيى بن عبد الحميد عن ابن المبارك والحديث في اصله مأبله مأخوذ من كتاب الزهد

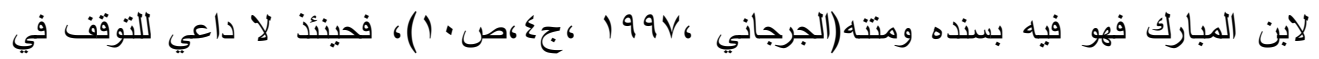
يحيى بن عبد الحميد وانما يكون البحث في من روى عنهم ابن المبارك هذا الحديث. والحديث ضعيف لان في اسناده دراج بن سمعان وهو ضعيف لاسيما في روايته عن ابي

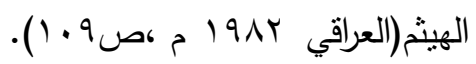

المبحث الثالث: متابعة الثقات له.

يمكن تعريف المتابعة بنوعيها القاصرة والتامة ، وقدعرفها العلماء في كتبهم كما هو مبين الان

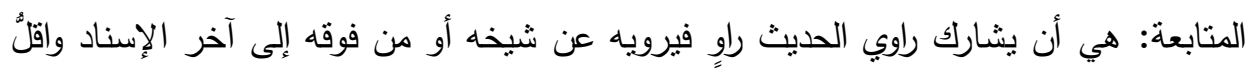

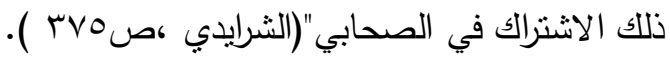

$$
\begin{aligned}
& \text { وهي على قسمين: }
\end{aligned}
$$

الأولى المتابعة التامة: وهي موافقة المتابع للمتابع في كامل الإسناد والمتن بحيث يلتقيان في الثيخ

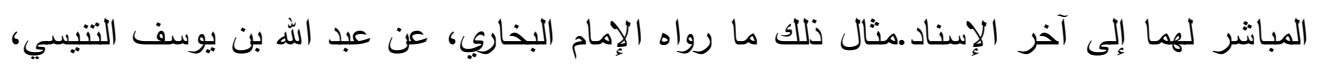


العدد الحادي والأربعون

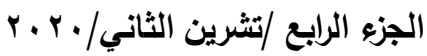

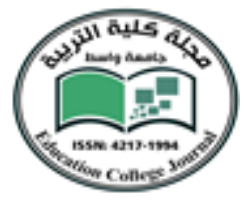

عن مالك، عن نافع، عن ابن عمر : " أن النبي - صلى الله عليه وسلم - نهى عن الشغار ".الإمام

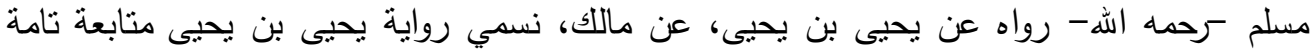
لرواية عبد الله بن يوسف؛ لأن يحيى بن يحيى وعبد الله بن يوسف نشاركا في الرواية عن مالك، فيحيى بن يحيى تابع عبد الله بن يوسف في شيخه اللي هو ماللك، فصارت متابعة تامة. نأني بعد نلك للمتابعة القاصرة، المتابعة القاصرة.. هذا الحديث ( نهى عن الثغار ) رواه عبيد اله

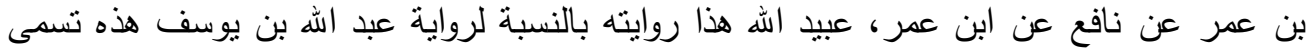
متابعة قاصرة؛ لأنه ما شارك عبد الله بن يوسف في شيخه، لكن نسمي رواية عبيد الله بن عمر لمالك رواية تامة، فهي تامة برواية مالك قاصرة بالنسبة لرواية عبد الله بن يوسف، فهذا يجتمع فيه الرواية

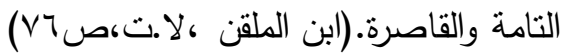
والثانية المتابعة القاصرة: وهي موافقة المتابع للمتابع في بعض الإسناد بحيث يلتقي معه في راوِ من رواة الإسناد في غير شيخه. فالراوي اذا كان ضعيفا وتابعه على روايته الثقات علم ان هذا الحديث هو من صحيح حديثه وانه لم يخطأ فيه والمتابعة اصل اصيل في باب قبول الرواية وردها، فهناك كثير ممن تكلم فيهم وضعف حديثهم قد نوبعو من قبل الثقات على بعض مرواياتهم فعلم انها مما ضبطوه وسامتل لنلك بمثال: اسحاق بن محمد بن اسماعيل الفروي: قال عنه الحافظ ابن حجر في النقريب: صدوق كفَّ فساء حفظه، وتعقبه صاحبا التحرير بقولهما: بل ضعيف يعتبر به(محاضرات الدورة المفتوحة الأولى

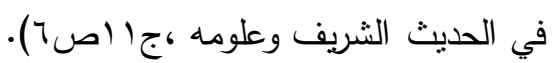

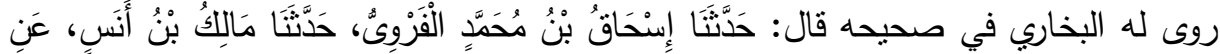

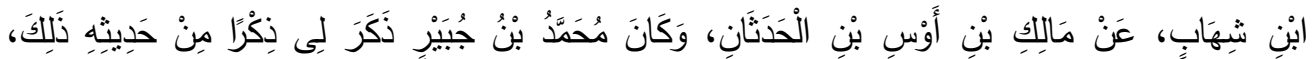

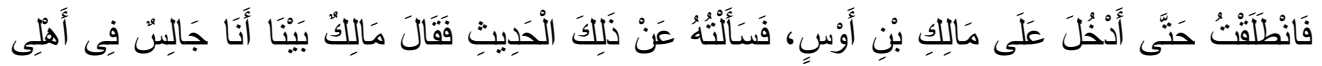

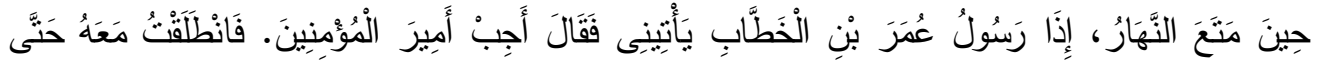

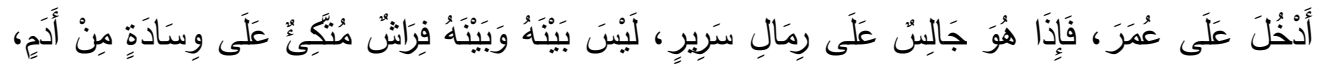

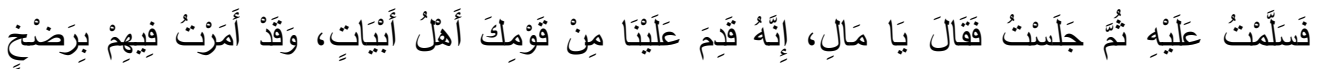

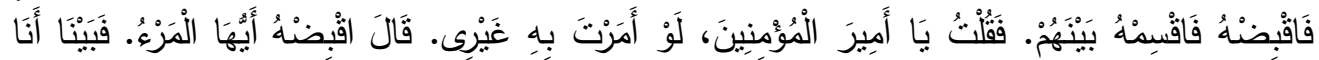

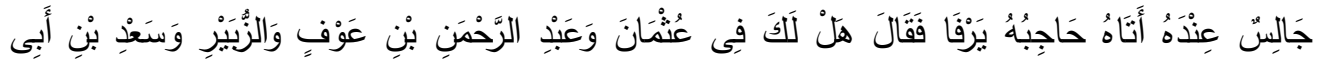

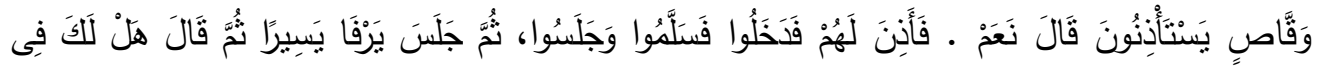

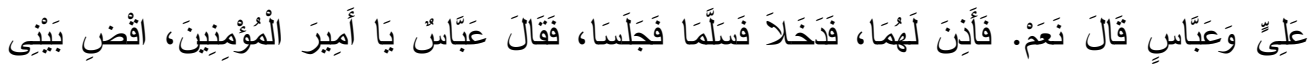




\section{العدد الحادي والأربعون

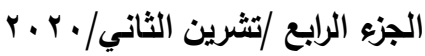

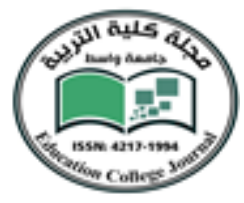

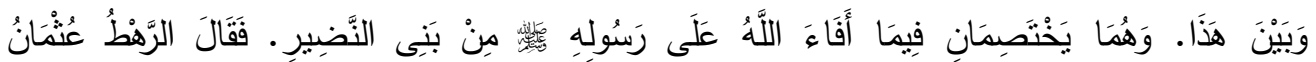

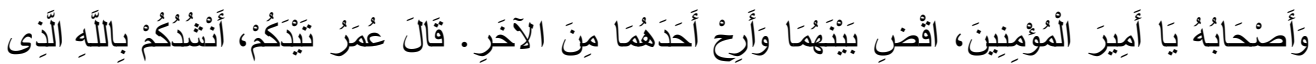

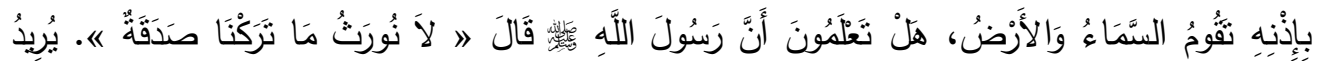
رَسُولُ اللَّهِ

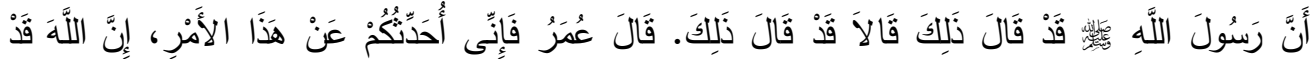

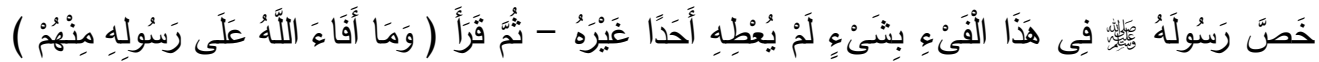

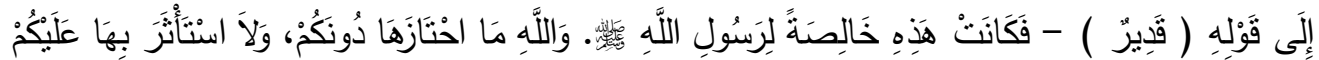

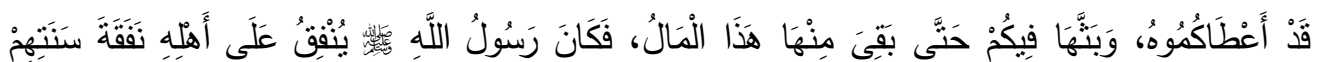

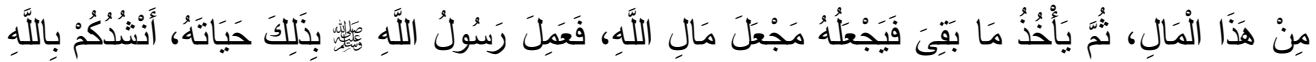

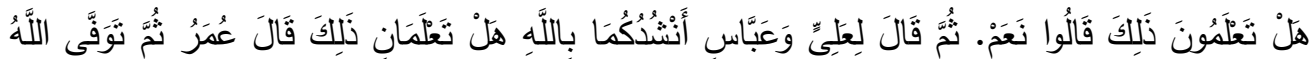

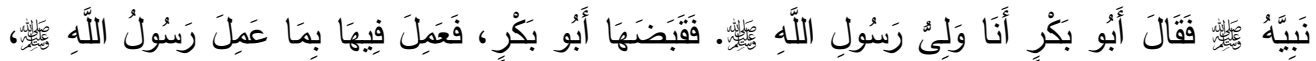

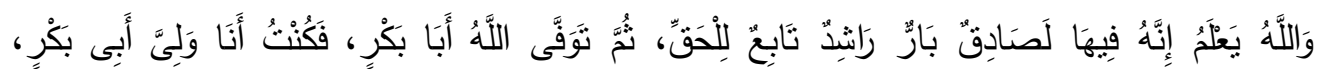

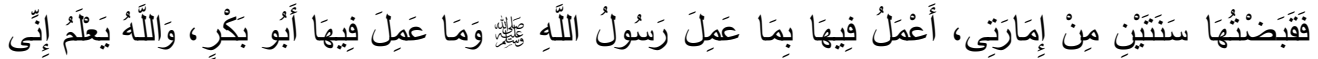

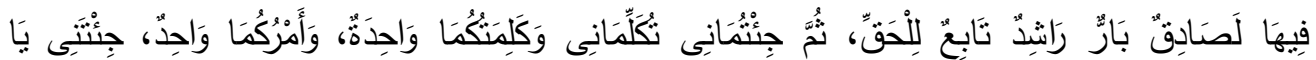

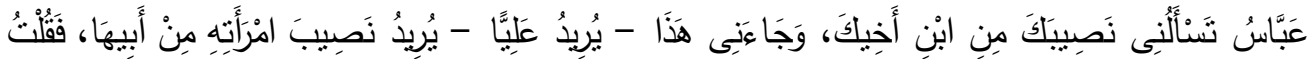
لَكَمَا إِنَّ رَسُولَ اللَّهِ

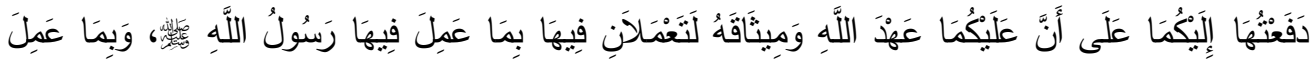

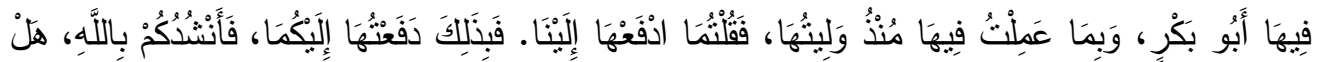

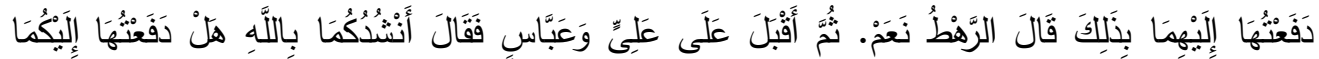

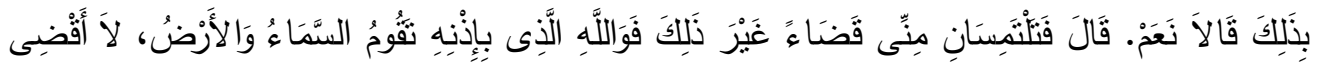

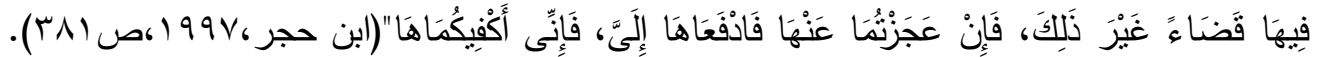

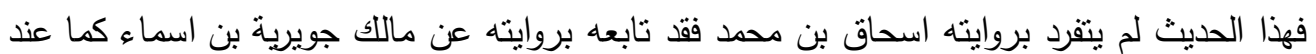

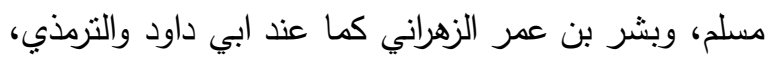

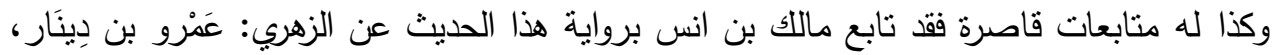

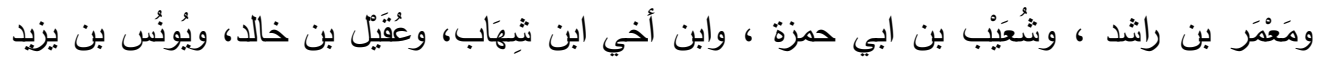

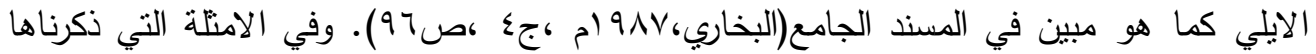


العدد الحادي والأربعون

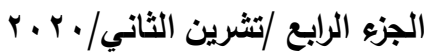

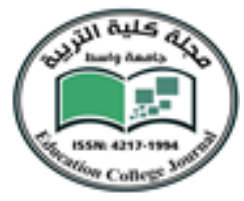

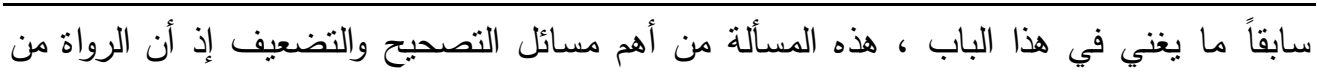
حيث القبول والرد ينقسمون إلى ثلاثة أقسام:

الأول: متفق على جلالتهم وإتقانهم، أو على توثيقهم جمهور الأئعة جهابذة هذا الثأن وفرسانها، فلا يلتقت إلى ما فيهم من جرح عام، وإنما ينظر إلى ما جرحوا فيه من جرح خاص يتعلق بالطعن في

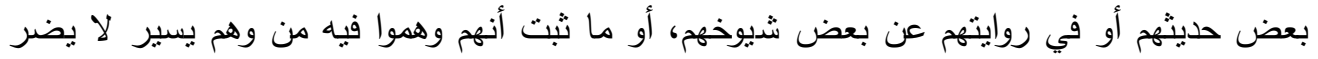

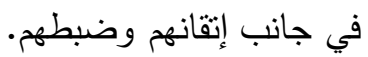

الثاني: قسم متفق على ضعفهم، أو على تضعيفهم جمهور أئمة هذا الثأن فلا يتلفت إلى توثيق من

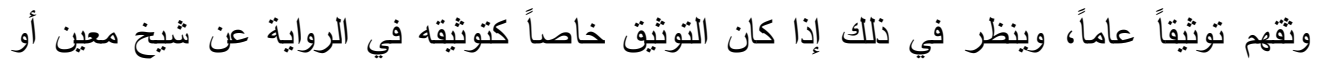
روايته لصحيفة معينة، أو ضبطه لحديث بعينه. القسم الثالث: وهم الرواة المختلف فيهم، وهنا مربط فرس المحققين، ومناخ رواحلهم، وهنا يجب

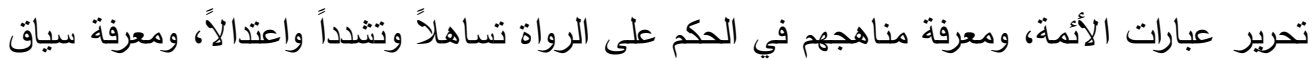
كلامهم في الراوي، وقرائن التجريح والتعديل. ومما ينبغي أن يعلم في هذا الثأن أنه لا يصلح أن يطرح حديث النايل الراوي أو يتوقف فيه، للاختلاف فيه، أو لإطلاق الكلام فيه، وإلا للزم تضعيف آنان فئ آلاف الأحاديث وردّها.

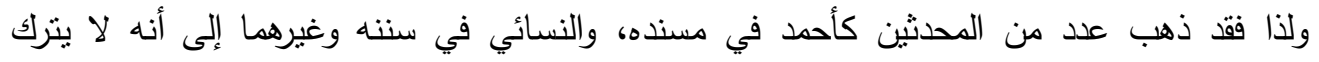
حديث الرجل حتى يجمع الجميع على تركه .وإذا لم يرد الحديث في كتب السنة المعتدة، ولم يروه

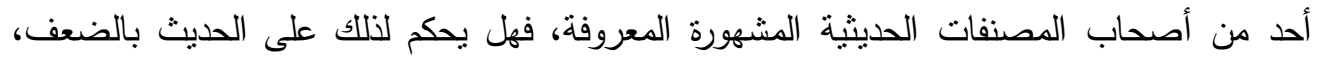

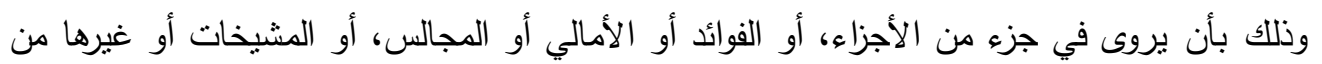

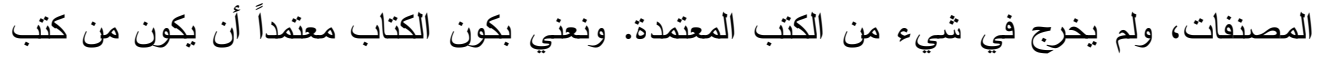
الحديث ويجمع بين صفتي التقام والثهرة، أبي التداول في أوساط العلماء، ويكون معروفاً مشهوراً

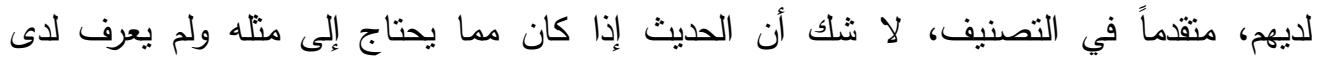

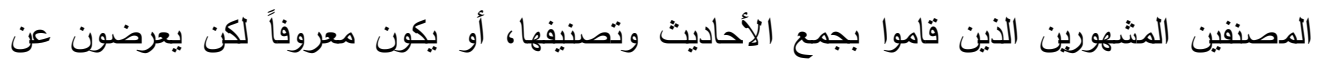

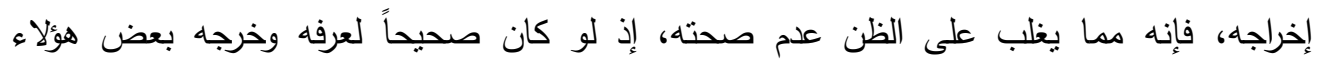

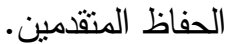

قال ابن الجوزي: فمتى رأيت الحديث خارجاً عن دواوين الإسلام كالموطأ، ومسند أحمد، والصحيحين، وسنن أبي داود ونحوها فانظر فيه فإن كان له نظير من الصحاح والحسان قرب أمره، وإن ارتبت فيه 
العدد الحادي والأربعون

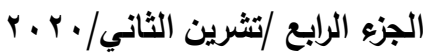

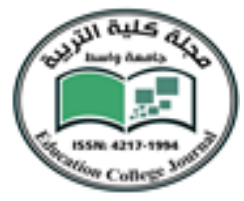

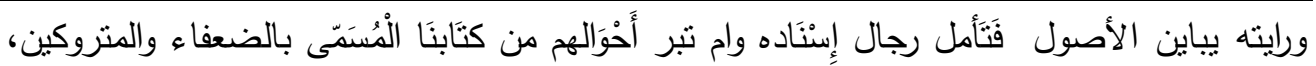

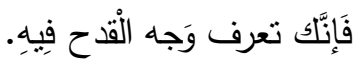

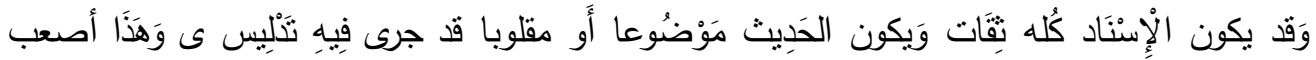

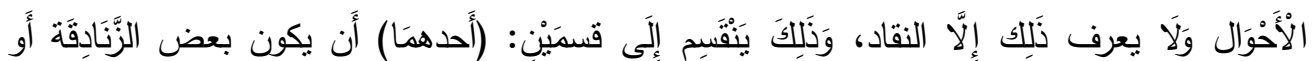

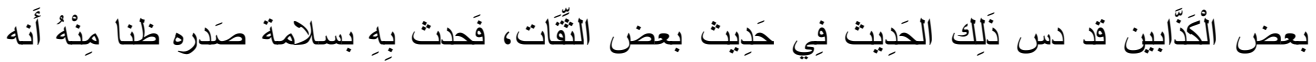

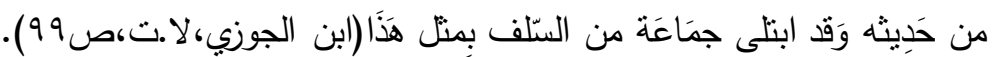

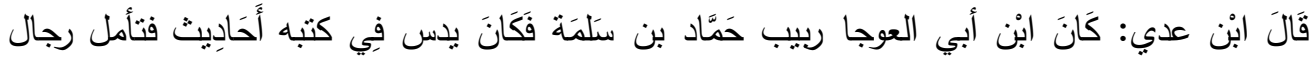

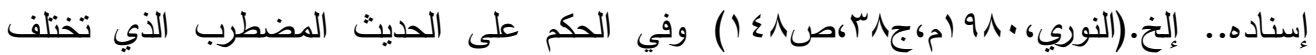
الرواية فيه فيروى على أكثر من وجه يخالف بعضها بعضاً وتكون منساوية في القوة، وقد يكون الراوي نفسه هو الذي روى هذه الوجوه، وقد يرويه بعض الرواة على وجه، وبعضهر على وجه آخر . فقد قالوا أنه يحكم بضعف الحديث المضطرب؛ لأنه دال على عدم ضبط الراوي أو الإخلاد بضبطه.

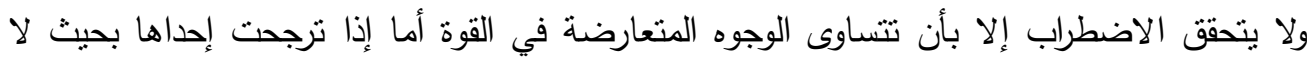

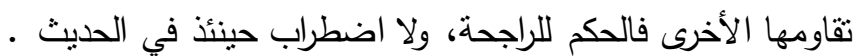
قال الخلال في جامعه في حديث ابن عباس في كفارة وطء الحائض قال الأ كأنه يعني الإمام أحمد -

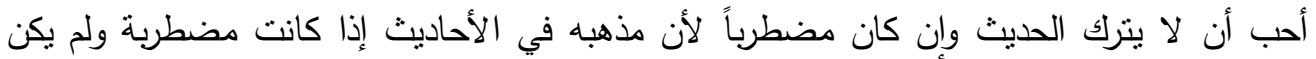

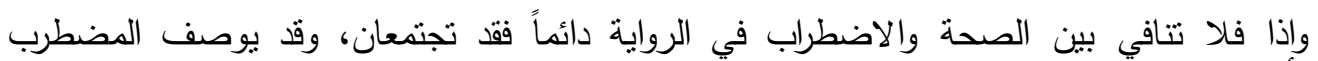
بالصحة أو بالحسن، وذلك بأن يقع الاختلاف في اسم رجل واحد وأبيه ونسبته ونحو ذللك، يكون نقة،

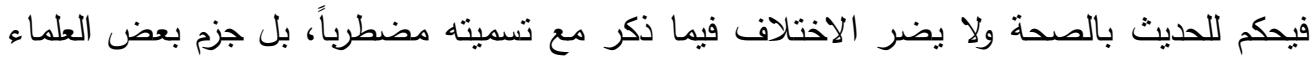
كالزركثي بذلك أيضاً في المقلوب والثاذ بأن يدخل القلب والثذذوذ والاضطراب في فئه فئه الصحيح

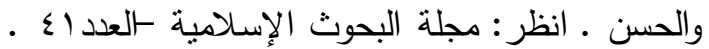
فهذه قواعد مهمة في التصحيح والتضعيف يجب على من يتصدر للفنتيا أو الحكم على الأحاديث

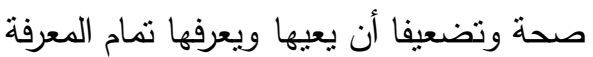


العدد الحادي والأربعون

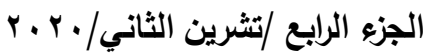
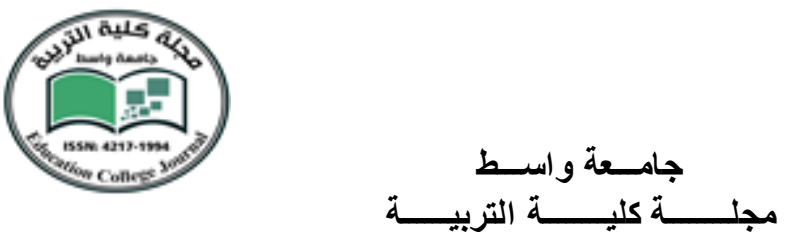

الخاتمة وأهم النتائج

يمكن وضع بعض النتائج التي تم استتناجها من هذا البحث :

ا -السنة النبوية وما فيها من احاديث رويت عن رسول الله صلى الله عليه وسلم قد قسمها العلماء الى اربعة اقسام اساسية هي الصحيح والحسن والضعيف والموضوع r-وضع العلماء شروط للعمل بالحديث الضعيف.

r- بينت اقوال العلماء في حكم الاحتجاج بالحديث الضعيف من خلال شروط وضعت له ـ. ع - ان الضعف بالرواية جاء نتيجة كثرت خطأ واوهام الراوي. ه- ترفض رواية راوي الحديث روايته من خلال اقوال المجرحين والمعدلين.

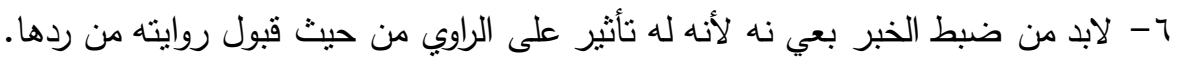
V- لكي تقبل رواي الراوي يجب ان يكون ثقة او حافظا او ثبت وغيرها من صفاة التعديل والجرح.

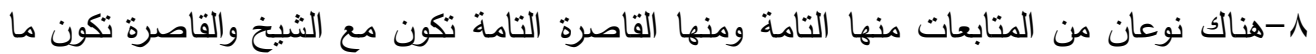
بعد الثيخ الذي يروي الحديث.

المصادر

القرآن الكريم

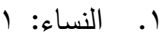

r.

r.

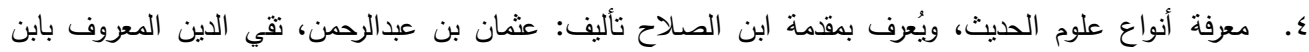

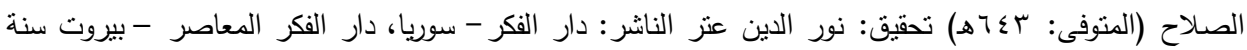

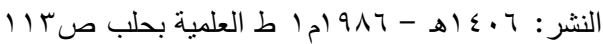

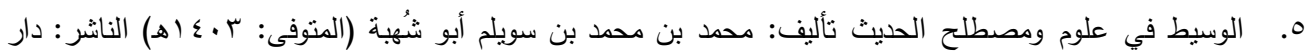

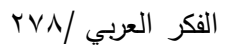

ז. منهج النقد في علوم الحديث تأليف: نور الدين محمد عتر الحلبي الناثر: دار الفكر دمثق سورية الطبعة: الطبعة

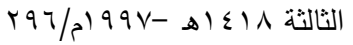

V. الاختصار علوم الحديث تأليف: أبو الفداء إسماعيل بن عمر بن كثير القرشي البصري ثم الدمقي (المتوفى:

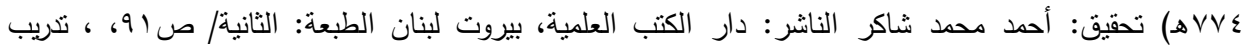

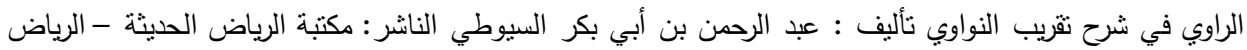

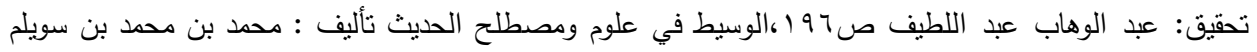

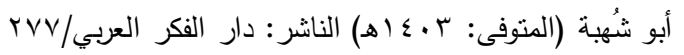


العدد الحادي والأربعون

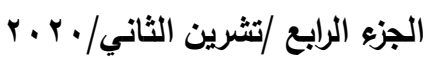

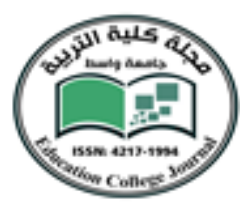

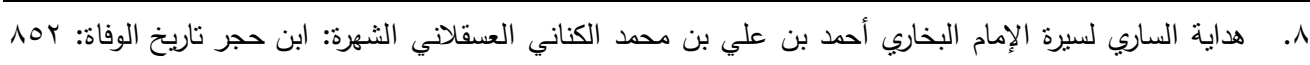

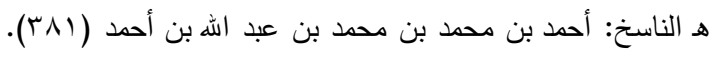

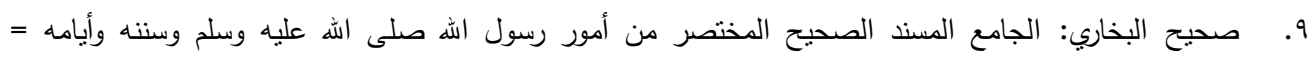
صحيح البخاري تأليف: محمد بن إسماعيل أبو عبداله البخاري الجعفي تحقيق: محمد زهير بن ناصر الناصي الناصر

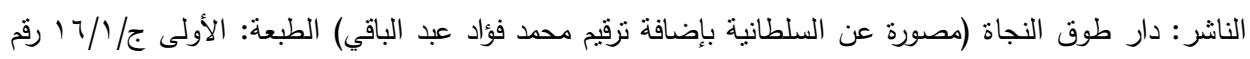

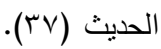

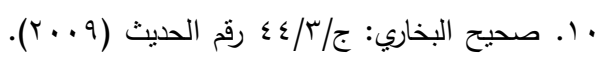

1ا. المسند الصحيح المختصر بنقل العدل عن العدل إلى رسول اله صلى الله عليه وسلم لمسلم بن الحجاج أبو الحسن الهن

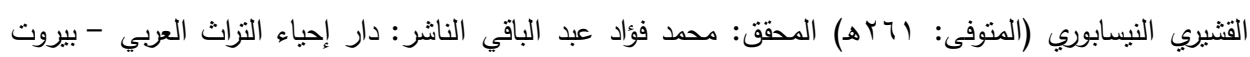

$$
\begin{aligned}
& \text { ج/ / / Trه رقم الحديث (V०a). }
\end{aligned}
$$

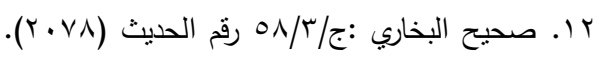

$$
\begin{aligned}
& \text { r. r.VA) }
\end{aligned}
$$

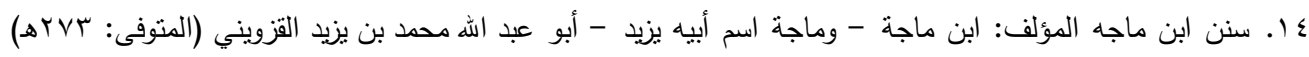

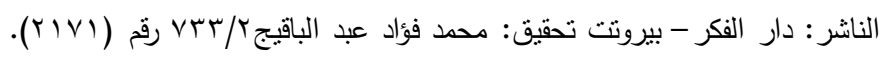

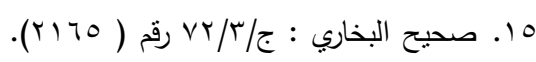

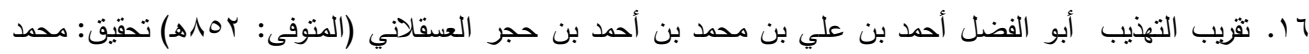

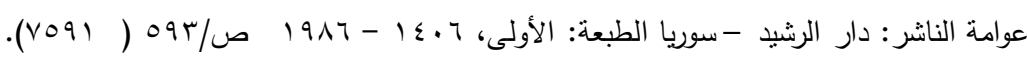

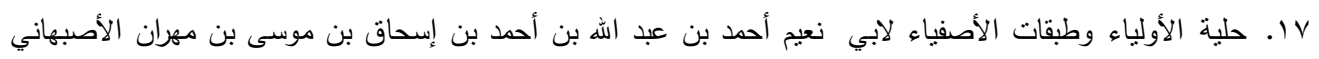

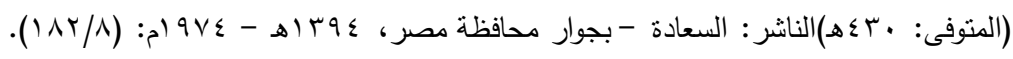

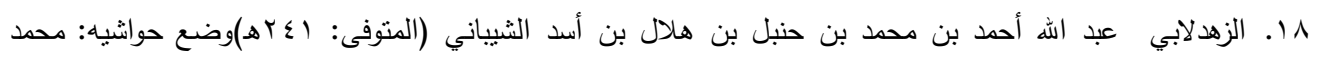

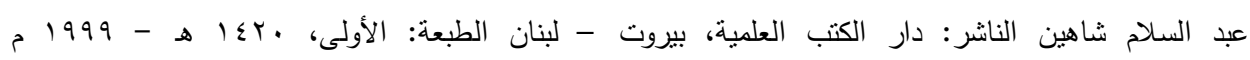

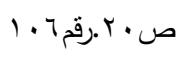

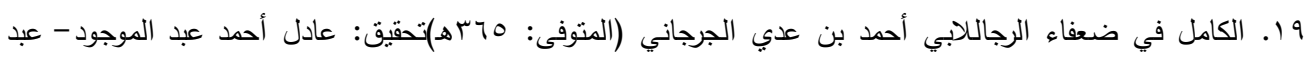

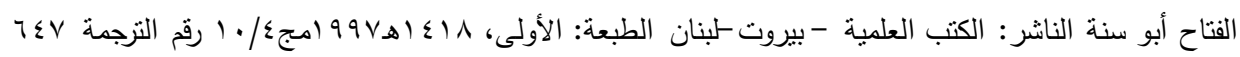

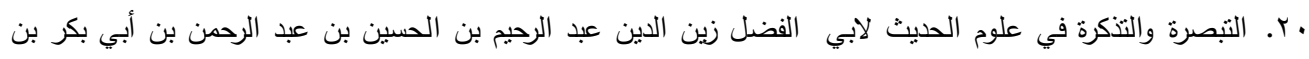

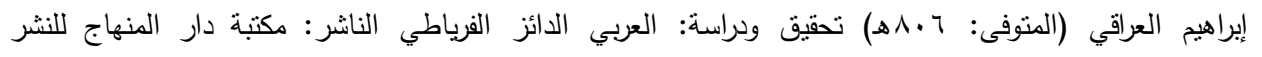

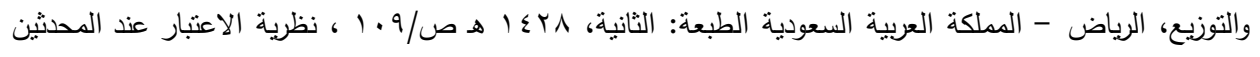

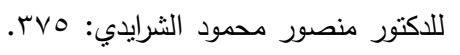

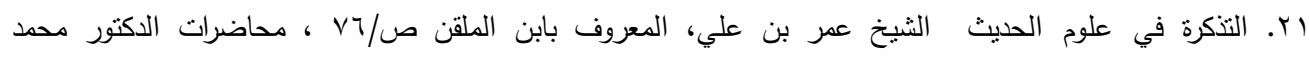

$$
\begin{aligned}
& \text { الطرهوني }
\end{aligned}
$$

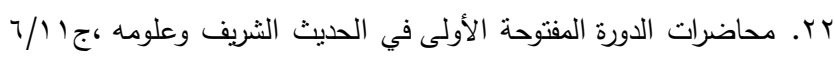

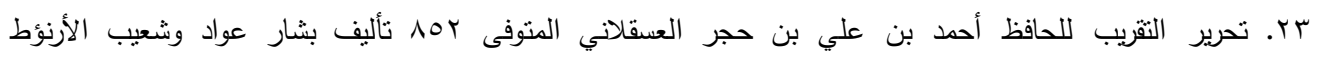

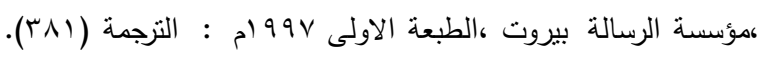


العدد الحادي والأريعون

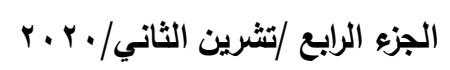

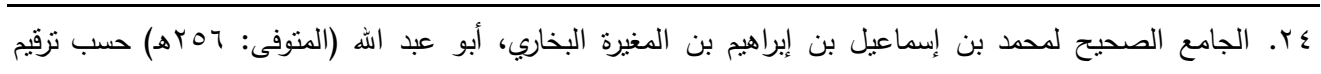

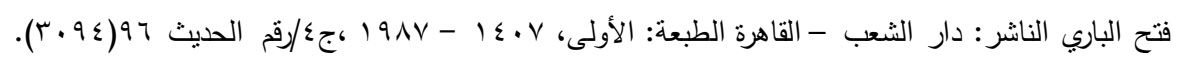

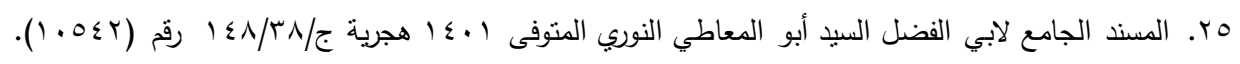

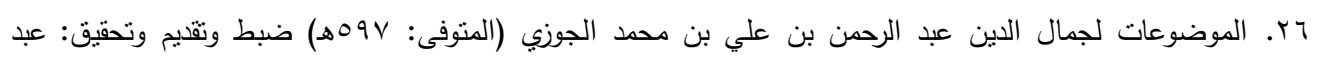

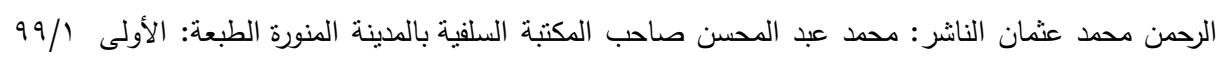

